\title{
AN ECONOMETRIC APPLICATION OF THE THEORY OF THE FARM-HOUSEHOLD*
}

\author{
Howard N. BARNUM \\ Center for Research on Economic Development, University of Michigan, Ann Arbor, \\ MI 48109, USA \\ Lyn SQUIRE \\ World Bank, Washington, DC 201433, USA
}

Recsived May 1977, final version recaived August 1978

\begin{abstract}
Employing a Conb-Douglas specification for the production function and a modified linear expenditure system, the paper presents an econometric model of household production, consumption and labor supply behaviour for a semi-commercial farm with a competitive labor market. The model, estimated from ps iary, cross-sectional, Malaysian data, is used to analyse the impact of migration, output price .ervention and technological change on the agricul...ral sector. In doing so, the wage-rate is treated as an endogenous variable to be determinud by the interaction of aggregate labor demand and supply curves obtained from the estimated micro functions.
\end{abstract}

\section{Introduction}

The theory of the farm-household ${ }^{1}$ has now achieved a prominent position in the development economics literature but data deficiencies have limited the number of empirical applications. ${ }^{2}$ As a result, little is known about the quantitative significance or about the policy implications of the theoretical integration of household production and consumption decisions. In this paper, we use primary cross section data to estimate a model of short-run household behaviour with the specilic intention of examining the policy significance of the theory of the farn-household. Our attention is particularly directed to the quantitative impact of changes in the following four exo-

*The views presented here are those of the authors and not those of the World Bank. The authors are grateful for the research assistance of Leain-Hong Ding.

'The seminal reference is Chayanov (1925); also see, Se!! (1966). Berry and Soligo (1968). Nakajima (1969), Khrishna (1969), and Jorgenson and Lau (1) 199 ).

${ }^{2}$ The only application known to the authors is the estimation of a farm-household model for Taiwan by Lau, Lin and Yotopoulos (1978). 
genous variables which have been of central importance in the theoretical literature involving the farm-household:

(i) the size of the family labor force. The model allows us to assess the impact of migration $\mathrm{c}^{\prime} \mathrm{h}$ household output, consumption and labor supply;

(ii) the price of the main agricultural output. Of interest here are the elasticities of both total output and marketed surplus;

(iii) techrology. Changes in farm technology are basic ingredients of all rural development strategies and can be expected to have major repercussions on household decisions; and

(iv) the wage-rate for agricultural labor. In particular, we are interested in the elasticities of household labor supply and demand for hired labor.

Total income or total expenditure is not included in the list of exogenous variables since the integration of the production and consumption decisions allows the model to determine both farm profit and wage income. It is this feature of the model which determines the policy significance of the farmhousehold theory. For example, consider a change in the price of the main agricultural output. Ignoring the production side of the model, the change in price will affect own-consumption of the output as well as the consumption of other items including leisure. If the production side of the model is introduced, however, the change in price will also affect farm output and hence farm profit and total household income, which will initiate a further change in the household's consurnption pattern. Thus, the production side of the model influences consumpt:on decisions through its impact on total household income and expenditure.

In section 2 we present a simple model of household behavior which includes the salient features of the prototypical farm-household and which reflects the production and institutional characteristics of rice producing households in the Muda River Valley of N.W. Malaysia. In section 3 we report the results of a production function analysis based on a CobbDouglas specification and derive a profit function. We then specify the consumption side of the model to conform to a mocified version of the linear expenditure system and present the results of estimation. In section 4 we provide an indication of the quantitative significance of the theory of the farm household by comparing selected consumption elasticities calculated first under the assumption that consumption and production decisions are independent and then under the more realistic assumption that consumption decisions are dependent on the household's production behavior. In section 5 we assess the policy significance of our results with respect to the four issues outlined above. The paper is summarized in section 6. Broadly, our analysis confirms the overall importance of the farm-household theory as a basic tool for the prediction of household response to a variety of exogenous changes. 


\section{A theory of household behavior}

The model of household behavior we present describes a semi-crimmercial family farm with a competitive labor market. ${ }^{3}$ It has been noted that the major part of world agriculture is consistent with this genre of model which is located intermediately on a continuum between a wholly commercial farm employing only hired labor and marketing all output and a pure subsistence farm using only family labor and producing no marketed surplus. ${ }^{4}$ In particular the essential characteristics of agriculture in our study region in N.W. Malaysia are consistent with this model.

The study area from which our sample was taken is in the Muda River Valley and comprises the state of Perlis and four administrative districts in the state of Kedah. An average household in the region retains about one fifth of agricultural production for household consumption and markets the remainder. Further, there is an active labor market for agricultural and other types of labor and all households participate in the labor market either as buyers or sellers of labor. Thus the use of labor time and the disposal of output are determined with reference to market wages and prices, and the average farm is aptly described as semi-commercial. It is also important for our choice of theoretical model that padi is grown on all farms included in the sample to the virtual exclusion of other crops, therefore making it unnecessary to estimate more than one production function to avoid the crop composition problems often encountered in production function studies in multicrop regions. Finally we note that land is rented by means of fixed charges and there are no sharecropping or other contractual arrangements which might lead to non-standard profit maximizing conditions.

With these points in mind, we formulate the household model as follows:

$$
\begin{aligned}
& U=U\left(L, C, M ; a_{i}\right), \quad i=1, \ldots, \\
& F=F\left(D, d_{j} ; A\right), \quad j=1, \ldots, \\
& T=H+L+D,
\end{aligned}
$$

and

$$
q M+p C=w H+R+p F-\sum w_{j} d_{j}
$$

where

$L=$ leisure,

$C=$ own-consumption of agricultural output,

$\boldsymbol{M}=$ consumption of market-purchased goods,

${ }^{3}$ This terminology has been suggested by Nakajima (1969).

${ }^{4}$ Khrishna (1969). 
$a_{i}=$ household characteristics (for example, number of dependents),

$F=$ total output of $C$,

$D=$ total labor input (both family and hired) used in $F$ production,

$d_{j}=$ other variable inputs used in $F$ production,

$A=$ area of land used in $F$ production,

$T=$ total household time available for labor,

$H=$ net quantity of labor time sold if $H>0$ and net quantity of labor time purchased if $\boldsymbol{H}<0$,

$R=$ non-wage, non-crop net other income,

$q=$ price of $M$,

$p=$ price of $C$,

$w=$ wage- $r$ ate,

$w_{j}=$ prices of other variable factors.

The household is assumed to maximise its utility function [eq. (1)] subject to a production function [eq. (2)] and time and income constraints [eqs. (3) and (4)].

The planning horizon is assumed to be one agricultural cycle. As a result, decisions relating to the total supply of household factors of production are treated as given. Thus migration, which affects total available household labor supply, is omitted from the analysis, as is the rent decision, which affects the total available household land supply. Land may, therefore, be treated as a fixed factor. P.ent payments or receipts, however, are captured in the definition of $R$, non-wage, non-crop net other income. Other long term decisions are also omitted from the analysis. In particular, it is assumed that the household has already made some decision about its desired level of saving and that this quantity is included in the definition of $R$. Finally, the analysis ignores risk, again on the grounds that, while risk may play a crucial role in the migration decision or the rent decision, it plays a less important role in the short term when it may be assumed that the longer term decisions have already been made and the household is, at least to some extent, conmitted to a fairly well-defined course of action for the duration of the agricultural cycle.

Maximising eq. (1) subject to eqs. (2) through (4) and eliminating the Lagrangian multipliers, yields the following first-order equations:

$$
\begin{aligned}
& U_{C} / U_{M}=p / q, \\
& U_{L} / U_{M}=w / q, \\
& p F_{D}=w, \\
& p F_{d_{j}}=w_{j}, \quad j=1, \ldots,
\end{aligned}
$$


and

$$
q M+p C+w L=\Pi+R+w T
$$

where

$$
\Pi=p F(D)-w D-\sum \ddot{w}_{j} d_{j}
$$

Eqs. (5) and (6) express the traditional first-order condition of welfare economics: that is, the marginal rate of substitution in consumption must equal the marginal rate of transformation in production. Eqs. (7) and (8) are the profit-maximising conditions for the allocation of labor and 0 ? 3 variable factors. Eq. (9) combines the income and time constraints as well as the technological constraint described by the production function. The lefthand side of eq. (9) includes the 'expenditure' on leisure and the right-hand side is an augmented version of Becker's (1965) concept of 'full income' which in this case includes the net profit $(\Pi)$ from household production.

Labor is singled out for separate treatment in eq. (7) to emphasize that the level of labor input is determined solely by the profit maximizing condition. In the absence of labor market participation the dichotomy between the production and consumption side would not be as complete. In this case the quantity of labor used in production would be affected directly by the subjective evaluation of work $^{5}$ to the household. However, with an active labor market the subjective evaluation of work determines the level of labor supplied by the household but not the household's total demand for labor in production. Instead total labor demand is determined by the profit maximizing condition and the production and consumption segments of the model can be estimated separately.

Given an independent estimate of the production function, eqs. (7) and (8) can be used to determine the variable inputs into $F$ production, and, since the land input is determined exogenously, the total output of $F$. The solutions for the variable inputs and $F$ can then be used to derive $\Pi$, net farm profit. Eqs. (7; and (8), therefore, represent the production side of the model, and the impact of production on the consumption side is then transmitted through the value of $\Pi$ in the income constraint. Turning to the consumption segment, if we assume that the second order conditions are satisfied, eqs. (5), (6) and (9) can be solved for demand functions for the three consumption goods, $C, M$ and $L$, in terms of the three prices, $q, p$ and $w$, the household characteristics, $a_{i}$, and total household expenditure, $E$, which is defined as the sum of $\Pi, R$ and $w T$. To implement the model econometrically it remains to specify the rorms of the production function and the consumption-expenditure system.

\footnotetext{
${ }^{5}$ See Sen (1966) and Chayanc $(1925)$.
} 


\section{The econometric model}

Recently, Lau, Lin and Yotopoulos (1978) have unified the production and consumption aspects of an agricultural household in an empirical model. Employing group means for farms in several regions of Taiwan they estimate the consumption parameters of a linear logarithmic expenditure system ${ }^{6}$ (LLES) and characterize household production activity with an estimated profit function. ${ }^{7}$ The general approach we follow parallels that of Lau et al.; however, the empirical specification we use departs from their specification in several respects which improve the model's applicability to policy analysis. First the production segment of our model employs a direct estimate of a production function. This has the advantage that we can use sample data on the intensity of factor use directly in the estimation of the production function ${ }^{8}$ rather than employing factor prices, which are not likely to vary greatly over a cross section sample, in the estimation of a profit function. Second we develop a modified version of the linear expenditure system which, unlike the LLES, does not restrain the elasticity of consumption with regard to expenditure to be unity. ${ }^{9}$ In section 4 we siall demonstrate the crucial role of the expenditure elasticities in linking the consumption and production sides of the farm-household model and, this, the importance of using an expenditure system which allows the budget shares to vary. Third, we employ a transformation introduced by Abbott and Ashenfelter (1976) which allows the direct estimation of a household labor supply function rather than the indirect derivation of a supply function from the household leisure demand function. This is desirable because it avoids major data problems which inevitably arise in defining leisure and therefore allows a more reliable estimate of household labor supply response. Finally we employ primary cross section data gathered at weekly intervals over a one year period and covering the time and income allocations of a set of households, which are homogeneous with respect to crop grown and soil quality.

\footnotetext{
${ }^{6}$ The linear logarithmic expenditure system is developed in Lau and Mitchell (1970).

${ }^{7}$ See Lau and Yotopotilos (1971) for an application of the profit function. The basic theoretical reference is McFadden (1970).

${ }^{8}$ It has been pointed out that direct estimates of a production function involve a potential simultaneous equations bias [Nowshirvani (1966)]. This criticism has been successfully answered by, among others, Zellner, Kmenta and Dreze (1966) who demonstrate that, given the lag between input decisions and output which occurs in agriculture, ordinary least squares will give unbiased estimates of the production function.

${ }^{9}$ The LES does imply that the ratio of the own pice elasticities to the expenditure elasticities will be approximately proportional across commodities [Deaton (1974)]. The proportionality restriction will, however, "only be close for all goods if the level of disaggregation adopted is high' [Deaton (1974, p. 340)]. For the present study the ratio of the price and income elasticities varies and the approximate proportionality restriction was not substantiated. This result is attributed to the fact that the budget share of each commodity is high and the level of disaggregation low.
} 
The production segment of the household model is introduced by deriving input demand functions and a profit function based upon an estimatid production function. The production function is specified in Cobb-Douglas form a:

$$
\text { - } F=\alpha_{0} A^{\alpha_{1}} D^{\alpha_{2}} V^{\alpha_{3}} K^{\alpha_{4}},
$$

where $K$ is the flow of capital services (machinery), and $V$ are the other variable inputs.

The estimated production function ${ }^{10}$ is

$$
F=19.11 A^{0.62} D^{0.29} V^{0.08} K^{0.01} .
$$

An analysis of allocational efficiency revealed that padi farmers in the study area maximise profits with respect to labor, machinery and other variable inputs and treat land as a fixed factor. Accordingly, we can derive demand iunctions for the three variable factors from eq. (11) and the profit maximization conditions, eqs. (7) and (8). For example, the total demand for padi labor is

$$
\begin{aligned}
D & =\alpha_{2}\left(p / w^{\prime}\right) F, \\
& =0.29(w / w) F .
\end{aligned}
$$

Substituting the demand functions in eq. (10) and rearranging yields an expression for the level of restricted ${ }^{11}$ farm profits $(\Pi)$ at different levels of output,

$$
\begin{aligned}
\Pi & =\alpha_{1} p F, \\
& =0.62 p F .
\end{aligned}
$$

Substituting the demand functions for the variable inputs in (11), the production function can be rewritten in terms of the fixed factors and the relative prices of $D, V$ and $K$ as

$$
\begin{aligned}
F & =\alpha_{0}^{1 / \alpha_{2}}\left(\prod_{j=2}^{4} \alpha_{j}^{\alpha_{j}}\right)^{1 / \alpha_{1}} \cdot A \cdot(p / w)^{\alpha_{2 / \alpha_{1}}}\left(p / w_{v}\right)^{\alpha_{3 / 2} \alpha_{1}}\left(p / w_{k}\right)^{\alpha_{1 / \alpha 1}}, \\
& =42.11 A(p / w)^{0.47}\left(p / w_{v}\right)^{0.13}\left(p / w_{k}\right)^{0.12} .
\end{aligned}
$$

${ }^{10} \mathrm{All}$ coefficients are significant at the $5 \%$ level, except that on the flow of capital services, $R^{2}$ $=0.67$, and returns to scale proved to be constant. The estimation of the production function and tests of allocational efficiency are discussed in Barnum and Squire (1978).

${ }^{11}$ Eq. (13) measures land's shire of output if each factor is paid its marginal product. 
Finaliy, substituting eq. (14) in eq. (13) gives an expression for profits, as a function of factor prices, which can now be incorporated in the household model as a component of the income side of total expenditure.

The consumption side of the household model is specified econometrically using the linear expenditure system. To differentiate between the use of time by dependents and working family members the system is developed in per capita terms. For an individual member of the family the utility function is written as

$$
U_{j}=\sum \beta_{i} \ln \left(x_{i}-\gamma_{i}\right), \quad j=1, \ldots, n,
$$

where $x_{i}$ indicates per capita consumption of the $i$ th commodity, and $\gamma_{i}$ are functions of a variety of household characteristics. Dependents are assumed to consume all their available time in the form of leisure and to consume the same quantities of other goods as do working family members. We further assume that the household utility function is identical for each member and additive across individuals, so that summing over the $n_{1}$ working family members and the $n_{2}$ dependents and substituting $t-s,\left(=L / n_{1}\right)$, for leisure consumption per working family member, the household consumption problem is to maximize

$$
\begin{aligned}
\sum U= & n_{1} \beta_{1} \ln \left(t-s-\gamma_{1}\right)+n_{2} \beta_{1} \ln \left(t-\gamma_{1}\right) \\
& +n \beta_{2} \ln \left(c-\gamma_{2}\right)+n \beta_{3} \ln \left(m-\gamma_{3}\right),
\end{aligned}
$$

subject to

$$
w L+p C+q M=E,
$$

where lower case letters indicate per capita amounts of $c$ and $m$, and $t$ is the total time available per individual, $s$ is the quantity of labor time supplied per family worker, and $n=n_{1}+n_{2}$.

Dividing through by $n$ the utility maximization problem may be written equivalently as

$$
\begin{aligned}
\operatorname{Max} U= & k \beta_{1} \ln \left(t-s-\gamma_{1}\right)+(1-k) \beta_{1} \ln \left(t-\gamma_{1}\right) \\
& +\beta_{2} \ln \left(c-\gamma_{2}\right)+\beta_{3} \ln \left(m-\gamma_{3}\right),
\end{aligned}
$$

subject to

$$
k w(t-s)+p c+q m=E / n,
$$

where $k=n_{1} / n$. If we let $\beta_{1}^{\prime}=k \beta_{1}$ and $w^{\prime}=k w$, then it is apparent that the problem is that of the standard linear expenditure system for which the 
expenditure equations are

$$
\begin{aligned}
& w(t-s)=\gamma_{1} w+\beta_{1}\left(E / n-w^{\prime} \gamma_{1}-p \gamma_{2}-q \gamma_{3}\right), \\
& p c=\gamma_{2} p+\beta_{2}\left(E / n-w^{\prime} \gamma_{1}-p \gamma_{2}-q \gamma_{3}\right) \\
& q m=\gamma_{3} q+\beta_{3}\left(E / n-w^{\prime} \gamma_{1}-p \gamma_{2}-q \gamma_{3}\right)
\end{aligned}
$$

This system can be altered to avoid a data specification error which could arise through the computation of leisure as the residual after time allocaied to work activities $(s)$ is subtracted from total discretionary time available ( $r$ ). The possible error occurs because of the necessity of making arbitrary assumptions with regard to subsistence time requirements in the definition of discretionary time. To avoid this problem we adopt a modification suggested by Abbott and Ashenfetter (1976), which involves substituting $t-\gamma_{s}$ for $\gamma_{1}$ in eq. (15). Substitution yields ${ }^{12}$ the estimating equations,

$$
\begin{aligned}
& -w s=-\gamma_{s} w+\beta_{1}\left(b+w^{\prime} \gamma_{s}-p \gamma_{2}-q \gamma_{3}\right), \\
& p c=\gamma_{2} p+\beta_{2}\left(b+w^{\prime} \gamma_{s}-p \gamma_{2}-q \gamma_{3}\right),
\end{aligned}
$$

and

$$
q m=\gamma_{3} q+\beta_{3}\left(b+w^{\prime} \gamma_{s}-p \gamma_{2}-q \gamma_{3}\right)
$$

where:

$$
b=-w^{\prime} s+p c+q m
$$

This transformation has the dual advantage that neither leisure nor totai available hours are included as variables and we obtain a direct estimate of the household labor supply function [eq. (16a)].

12 Expanding eq. (15a) yields

$$
\begin{aligned}
w t-w s & =\gamma_{1} w+\beta_{1}\left[(1 / n)(w L+p C+q M) \cdots w^{\prime} \gamma_{1}-p \gamma_{2}-q \gamma_{3}\right] \\
& =\gamma_{2} w+\beta_{1}\left[w^{\prime}\left(L / n_{1}\right)+p c+q m-w^{\prime} \gamma_{1}-p \gamma_{2}-q \gamma_{3}\right] .
\end{aligned}
$$

Substituting $L / n_{1}=t-s$ and $\gamma_{1}=t-\gamma_{s}$ we obtain

$$
w t-w s=w t-\gamma_{s} w+g_{1}\left[w^{\prime} t-w^{\prime} s+p c+q m-w^{\prime} t+w^{\prime} \gamma_{s}-p \gamma_{2}-q \gamma_{3}\right] \text {. }
$$

which can be rearranged to form eq. (16a). Similar derivations can be used to obtain eqs. (16b) and $(16 c)$. 
To simplify, we can write the system in matrix notation as

or

$$
\begin{aligned}
{\left[\begin{array}{c}
-w s \\
p c \\
q m
\end{array}\right]=} & {\left[\begin{array}{lll}
b & 0 & 0 \\
0 & b & 0 \\
0 & 0 & b
\end{array}\right] \cdot\left[\begin{array}{l}
\beta_{1} \\
\beta_{2} \\
\beta_{3}
\end{array}\right] } \\
& +\left[\begin{array}{ccc}
w^{\prime}\left(\beta_{1}-1 / k\right) & -p \beta_{1} & -q \beta_{1} \\
w^{\prime} \beta_{2} & p\left(1-\beta_{2}\right) & -q \beta_{2} \\
w^{\prime} \beta_{3} & -p \beta_{3} & q\left(1-\beta_{3}\right)
\end{array}\right] \cdot\left[\begin{array}{l}
\gamma_{s} \\
\gamma_{2} \\
\gamma_{3}
\end{array}\right],
\end{aligned}
$$

$$
Y=B \beta+P \gamma .
$$

Household characteristics are introduced ${ }^{13}$ by making the vector of $\gamma^{\text {'s a }}$ linear function of a vector of household characteristics $G$,

or

$$
\left[\begin{array}{l}
\gamma_{s} \\
\gamma_{2} \\
\gamma_{3}
\end{array}\right]=\left[\begin{array}{lllll}
\delta_{10} & \delta_{11} & \delta_{12} & \delta_{13} & \delta_{14} \\
\delta_{20} & \delta_{21} & \delta_{22} & \delta_{23} & \delta_{24} \\
\delta_{30} & \delta_{31} & \delta_{32} & \delta_{33} & \delta_{34}
\end{array}\right] \cdot\left[\begin{array}{l}
1 \\
n_{1} \\
n_{2} \\
e \\
a
\end{array}\right]
$$

$$
\gamma=\delta G .
$$

Thus the final system of equations to be estimated can be written as

$$
Y=B \beta+P \delta G \text {. }
$$

Because the elements of $\delta$ appear in each of the three expenditure equations [note that $\gamma_{s}, \gamma_{2}$ and $\gamma_{3}$ each appear in (15a), (15b) and (15c)] we choose an estimation procedure which constrains the estimates of $\delta$ to be consistent across equations. Further, since the marginal budget shares sum to one, $\beta_{1}^{\prime}+\beta_{2}+\beta_{3}$ must equal unity; that is, an estimate of $\beta_{1}^{\prime}$ can be obtained from estimates of $\beta_{2}$ and $\beta_{3}$. Therefore it is necessary to estimate only the second two equations in the system in order to derive a complete set of estimated parameters and we can eliminate the first row in $Y, B, \beta$ and $P$ for purposes of estimation. ${ }^{14}$

The model is estimated for households in the Muda River Valley of Malaysia using the primary cross section data described in the appendix. In our sample neither $p$ nor $q$ varies but in the system describec by eq. (17) variation is required in only one price ( $w$ in our analysis), in addition to househoid characteristics and expenditures, for all parameters to be de-

${ }^{13}$ See Theil (1975).

${ }^{14}$ ibid. 
termined. Estimation of the system proceeds under the assumption that the disturbance terms in each equation are independent and have zero means and uniform variances. We apply ordinary least squares using a modification of the iterative least squares procedure used by Stone (1954). Setting $\beta_{2}$ and $\beta_{3}$ equei to their values obtained from unconstrained estimation, the $P$ matrix is constructed and ordinary least squares is used to estimate the $\delta$ and $\beta$ matrices. The new values of $\beta_{2}$ and $\beta_{3}$ are then used to reconstruct $P$ and the procedure continues iteratively until convergence is obtained. Convergence occurred in less than ten iterations and the resulting coefficients proved remarkably consistent with unconstrained estimates of the three equations.

After a preliminary set of results was obtained, variables with coefficients which were not significant at least at the ninety percent confidence level (using a one-tailed $t$-test) were dropped and the system was reestimated. Specifically, none of the coefficients on age $(a)$ were found to be significant; with regard to family labor force $\left(n_{1}\right)$ only $\delta_{11}$ was found to be significant; and with regard to education (e), $\delta_{13}$ and $\delta_{33}$ were found to be significant. The final parameter estimates are reported in table 1 . The signs of all coefficients are significant at above the ninety-five percent confidence level.

Table 1

Estimated parameters of the linear expenditure system for an agricultural household in Malaysia."

\begin{tabular}{lcc}
\hline Coefficient & Estimate & $T$-statistic \\
\hline$\beta_{1}{ }^{0}$ & 0.30 & \\
$\beta_{2}$ & 0.05 & 2.72 \\
$\beta_{3}$ & 0.78 & 32.61 \\
$\delta_{10}$ & 79.87 & 16.93 \\
$\delta_{20}$ & 76.66 & 8.62 \\
$\delta_{30}$ & 131.36 & 3.10 \\
$\delta_{11}$ & -9.35 & 8.74 \\
$\delta_{12}$ & +2.18 & 2.43 \\
$\delta_{13}$ & -1.83 & 4.72 \\
$\delta_{22}$ & -5.02 & 2.09 \\
$\delta_{21}$ & -20.53 & 2.06 \\
$\delta_{33}$ & 7.45 & 2.31 \\
\hline \multicolumn{2}{c}{$N=207}$. \\
'Derived from the restriction that $k \beta_{1}+\beta_{2}+\beta_{3}=1$. In calculating $\beta_{1}$, \\
$k$ was set at its mican value of 0.56.
\end{tabular}

The per capita expenditure functions may be obtained by substituting the results of table 1 into eq. (17). The family expenditure functions may then be derived by multiplying the labor supply function by $-n_{1}$ (the number of 
working family members) and the expenditure functions for padi and nonfarm goods by $n$ (the number of family membersi. The final set of household equations may be written as follows:

$$
\begin{aligned}
{\left[\begin{array}{l}
w S \\
p C \\
q M
\end{array}\right]=} & \left(E-w n_{1} t\right)\left[\begin{array}{lll}
k & 0 & 0 \\
0 & 1 & 0 \\
0 & 0 & 1
\end{array}\right]\left[\begin{array}{r}
-0.30 \\
0.05 \\
0.78
\end{array}\right] \\
+n & {\left[\begin{array}{rrrr}
(1-0.30 k) & w k & 0.30 k p & 0.30 k q \\
0.05 & w k & 0.95 p & -0.05 q \\
0.78 & w k & -0.78 p & 0.22 q
\end{array}\right] } \\
& \times\left[\begin{array}{rrrr}
-79.87 & 9.35 & -2.18 & 1.83 \\
76.66 & 0 & 5.02 & 0 \\
131.36 & 0 & -20.53 & 7.45
\end{array}\right]\left[\begin{array}{l}
1 \\
n_{1} \\
n_{2} \\
e
\end{array}\right] .
\end{aligned}
$$

\section{The interaction of production and consumption decisions}

An important feature of the theoretical model of farm household behavior lies in the recognition that the household response to a change in an exogenous variable consists both in a restructuring of consumption patterns attributed to expenditure and consumption substitution effects and in a production response. Estimates of the impact of changes in, for example, labor market conditions or padi prices are apt to be more accurate if based on a complete farm household model than if they are based on either the consumption or production segments alone. To gain an indication of the quantitative significance of the integrated model, we first derive partial household response elasticities under the assumption that net farm profit, $\Pi$, is exogenous, thereby ignoring the production side of the model. Then we derive total response elasticities for the full model by inserting the profit function into the expenditure equation, thereby allowing profits to be determined endogenously and incorporating the production side of the model.

The complete household model consists, on the consumption side, of the demand functions which can be derived from the first order conditions, and the expenditure constraint,

$$
E=\Pi+w_{1} n t+R,
$$

and on the production side, of the profit function derived from the production function and irst order profit maximizing conditions. Or in terms of the estimated system, the complete model consists of the demand functions 
which can be derived directly from eq. (18), and the profit function (13) with $F$ given as written in eq. (14).

Total ${ }^{t} y$ differentiating the full system of household equations and rewriting allows the derivation of the set of total response elasticities which give the proportional change in any endogenous variable, $Y$, in response to a proportional change in an exogenous variable, $X$. The total response elasticities can be broken down into component partial elasticities,

$$
\begin{aligned}
\frac{\partial Y}{\partial X} \cdot \frac{X}{Y}(\Pi \text { variable })= & \frac{\partial Y}{\partial X} \cdot \frac{X}{Y}(\Pi \text { constant }) \\
& +\left(\frac{\partial Y}{\partial E} \cdot \frac{E}{Y}\right)\left(\frac{\partial E}{\partial \Pi} \cdot \frac{\Pi}{E}\right) \cdot\left(\frac{\partial \Pi}{\partial X} \cdot \frac{X}{\Pi}\right)
\end{aligned}
$$

or, using a more concise notation,

$$
\eta_{Y X}=\eta_{Y X}^{*}+\eta_{Y E} \cdot \eta_{E \Pi} \cdot \eta_{\Pi X}
$$

where $\eta_{Y X}$ represents the elasticity obtained if farm profits are allc viv to vary and $\eta_{Y X}^{*}$ represents the elasticity obtained if farm profits are held constant. A simple measure of the significance of integrating production and consumption decisions can be obtained by comparing $\eta_{Y X}$ and $\eta_{Y X}^{*}$ elasticities computed for chosen dependent and independent variables. Given that we have chosen to partition the total elasticity using the variability of profits as a criterion it is useful to compare elasticities for exogenous variables which are arguments in the profit function. ${ }^{15}$

Table 2 presents elasticities, calculated at the arithmetic means of the sample used for estimation, for household consumption of padi $(C)$, non-farm goods $(M)$, and household labor supply $(S)$ with respect to the price of padi $(p)$, the wage rate $(w)$ and the neutral technical efficiency parameter $\left(\alpha_{0}\right)$. Comparing the values of $\eta_{Y X}^{*}$ and $\eta_{Y X}$ we note that of the nine pairs of elasticities, six have a change in sign depending on whether or not profit is endogenous. Comparing by exogenous variable we note that all of the ela:ticities with respest to price have different signs and of these twro differ by at least \pm 0.5 . All of the elasticities with respect to the wage rate also have a

\footnotetext{
${ }^{15} \mathrm{An}$ assessment of the quantitative significance of the farm household model could be carried out with other variants of the procedure summ n rized by eq. (19). For instance, one could compare elasticities obtained by first holding expenditure (instead of profits) constant and then allowing expenditure to vary. In this case, for the set of elasticities with expenditize conslant changes in, say, $n_{1}$ would not affect expenditure although clearly the total value of dicretionary: time, $w n_{2} t$, would have increased. We have chosen as more insiructive, to hold farm profits constant since this is the most likely procedure to be followed by an economist who wishes to calculate farm response elasticities, is cognizant of the role of the expenditure constrant, and who has data on the consumption side of the model but who lacks information a yout the produstion variables.
} 
Table 2

Selected household response elasticities with farm profits alternatively erogenous and endogenous."

\begin{tabular}{|c|c|c|c|}
\hline \multirow[b]{2}{*}{$\begin{array}{l}\text { Exogenous } \\
\text { variable }\end{array}$} & \multicolumn{3}{|l|}{ Endogenous variable } \\
\hline & $\begin{array}{l}\text { Own consumption } \\
\text { of padi } \\
\text { (C) }\end{array}$ & $\begin{array}{l}\text { Consumption of } \\
\text { non-farm goods } \\
(M)\end{array}$ & $\begin{array}{l}\text { Labor } \\
\text { supply } \\
(S)\end{array}$ \\
\hline \multicolumn{4}{|l|}{ Price of padi $(p)$} \\
\hline$\eta_{Y p}^{*}$ & -0.04 & -0.27 & 0.08 \\
\hline$\eta_{Y p}$ & 0.38 & 1.94 & -0.58 \\
\hline \multicolumn{4}{|l|}{ Wage rate $(w)$} \\
\hline$\eta_{r_{w}}^{*}$ & 0.06 & 0.29 & -0.07 \\
\hline$\eta_{\mathbf{Y}_{w}}$ & -0.08 & -0.35 & 0.12 \\
\hline \multicolumn{4}{|l|}{$\begin{array}{l}\text { Neutral technology } \\
\text { parameter }\left(\alpha_{0}\right)\end{array}$} \\
\hline$\eta_{r \alpha_{0}}^{*}$ & 0 & 0 & 0 \\
\hline$\eta_{Y a_{0}}$ & 0.42 & 2.21 & -0.65 \\
\hline Total experıditıre $(E)$ & 0.52 & 2.74 & -0.81 \\
\hline
\end{tabular}

${ }^{a}$ The elasticities are computed at the mean values of the variables. $\eta_{Y X}^{*}$ represents elasticities computed under the assumption that net farm profit is exogenous. $\eta_{Y X}$ represents elasticities computed with profits endogenous. The components of $\eta_{Y X}$ are obtained as follows: $\eta_{Y X}^{*}$ and $\eta_{Y E}$ are computed from eq. (18); and $\eta_{E \Pi}$ equals $\Pi / E$. $\eta_{n X}$ is computed from eqs. (13) and (14).

change in sign, ${ }^{16}$ although the absolute values of the differences are not as great as for price. We conclude that, for our study area, the theory of the farm household is of considerable importance when examining the likely impact of changes in the price of the main agricultural output, and is also of importance, although relatively less so, when looking at the impact of changes in the wage rate.

We also note that the theory of the farm household is important when examining the likely impact of a neutral shift in the production function. For neutral changes in technology, the first term in eq. (19) equals zero since, with the production side of the model excluded, consumption is independent of technology. The second term is, however, potentially large since farm profits are highly elastic with respect to changes in the neutral technological

\footnotetext{
${ }^{16}$ In particular note that with the profit function excluded the labor supply schedule with respect to the wage rate is negative, a fact which is consistent with the results sr:ved by Barzel and MacDonald (1973) for households with a homothetic utility function and insufficient asset income to provide for minimum subsistence levels of consumption. This negative response is more than offset by the inclusion of the production side of the model; with the addition of the profit function the supply response is positive. Since four-fifths of all labour in the Muda valley comes from farm households one can expect that the aggregate labor market response is positive. This issue is discussed further in the subsequent section.
} 
parameter of the production function. ${ }^{17}$ The extent of the overall impact on $C, M$ or $S$ depends crucially on the size of the expenditure elasticity (see table 2) for the endogenous variable question.

Exariining the table by endogenous variable, it can se noted that the elasticities of $M$ and $S$ have the greatest change in magnitude with the incorporation of the profit function. The distinguishing feature of these two variables is that they have, in absolute terms, the highest expenditure elasticities of the three variables considered. These results give a quantitative basis to the observation made above of the importanc; of the expenditure elasticities and the necessity of using a consumption system which will allow unrestricted estimates of the expenditure elasticities. ${ }^{18}$ The results also indicate that the theory of the farm household is quantitatively important (in terms of the differences between elasticities based on only the consumption side of the model and elasticities derived from the integrated model) if either the expenditure elasticity is absolutely large (as is the case, in this study, for non-farm goods and labor supply) or if the impact of a change in an exogenous variable on farm profits is large (as is the case of a change in output price or technology); the theory is especially important in the event that both occur simultaneously (as is the case of the elasticity of demand for non-farm goods with respect to changes in output price or technology).

\section{Policy conclusions}

Up to this point we have used the estimated response elasticities to demonstrate the significance of the theory of the farm household and the importance of the expenditure elasticities. We now use our results to draw a variety of policy conclusions with respect to migration, the effect of output price intervention on marketed surplus, and the income distributional implications of changes in output price and technology. Other results may bc derived from the estimated model but the ones described here appeared to us to be of particular interest. The policy analysis is based on ti.c response elasticities, for the integrated model, presented in table 3.

In each of the applications considered it is necessary to distinguish between the response of an individual household and the aggregate market response. Thus, the elasticities computed from the household model show the impact of a change in an exogenous variable on household behavior when all

\footnotetext{
${ }^{17} \eta_{\Pi \alpha 0}=1.61$.

${ }^{18}$ We also estimated the consumption side of the model using the linear logarithmic expenditure system applied by Lau et al. (1978). For most of the endogenous variables the response elasticities obtained from the consumption segment of the model are similar in magnitude for both the LLES and LES systems but the total response elasticities obtained from the two systems differ greatly when the production side is incorporated. The difference is attributable to the fact that the LLES restricts the expenditure elasticities to be unity while the LES only restricts the expenditure elasticities to be positive.
} 
Table 3

Selected household response elasticities."

\begin{tabular}{|c|c|c|c|c|c|c|c|}
\hline \multirow[b]{2}{*}{$\begin{array}{l}\text { Exogenous } \\
\text { variable }\end{array}$} & \multicolumn{7}{|c|}{ Endogenous variable } \\
\hline & $\begin{array}{l}\text { Own con- } \\
\text { sumption of } \\
\text { padi }(C)\end{array}$ & $\begin{array}{l}\text { Consump- } \\
\text { tion of } \\
\text { non-farm } \\
\text { goods }(M)\end{array}$ & $\begin{array}{l}\text { Labor } \\
\text { supply } \\
(S)\end{array}$ & $\begin{array}{l}\text { Labor } \\
\text { demand } \\
\text { (D) }\end{array}$ & $\begin{array}{l}\text { Output } \\
\text { (F) }\end{array}$ & $\begin{array}{l}\text { Marketed } \\
\text { surplus } \\
(F-C)\end{array}$ & $\begin{array}{l}\text { Farm } \\
\text { profit } \\
(I)\end{array}$ \\
\hline $\begin{array}{l}\text { Number of } \\
\text { working family } \\
\text { members }\left(n_{1}\right)\end{array}$ & 0.44 & -0.06 & 0.62 & - & - & -0.08 & - \\
\hline $\begin{array}{l}\text { Price of } \\
\text { padi }(p)\end{array}$ & 0.38 & 1.94 & -0.58 & 1.61 & 0.61 & 0.66 & 1.61 \\
\hline $\begin{array}{l}\text { Neutral } \\
\text { technology } \\
\text { parameter }\left(\alpha_{0}\right) \\
\text { Wage rate }(w)\end{array}$ & $\begin{array}{r}0.42 \\
-0.08\end{array}$ & $\begin{array}{r}2.21 \\
-0.35\end{array}$ & $\begin{array}{r}-0.65 \\
0.12\end{array}$ & $\begin{array}{r}1.61 \\
-1.47\end{array}$ & $\begin{array}{r}1.61 \\
-0.47\end{array}$ & $\begin{array}{r}1.85 \\
--0.55\end{array}$ & $\begin{array}{r}1.61 \\
-0.47\end{array}$ \\
\hline
\end{tabular}

aThe elasticities are derived from the integrated model and are computed at mean values of the variables.

other exogenous variables are held constant, and an attempt to draw macro, general equilibrium conclusions must face the problems of aggregation and of the macro interdependency among variables which at the micro level can be treated as exogenous. To allow an extrapolation of the micro analysis to the market level, it is assumed that the relevant aggregate relationships can be obtained by multiplying the corresponding microeconomic relationships by the total number of households in the padi sector or equivalently, rather than attempting a numerical aggregation we assume that the estimated model describes a representative household. It is also assumed that the only macro economic interdependency between variables which are exogenous at the micro level is between the wage rate and all other variables. To justify this assumption, we note that the prices of the main inputs and outputs, including padi and the prices of many consumer items are determined in world markets, subject to tariff policy. Other variables which are exogenous at the micro level (that is, family labor force, number of dependents, area operated, etc.) are also exogenous at the macro level, because our focus is on the short-run during which period these variables may be considered fixed. ${ }^{19}$

The equation for labor market equilibrium for the representative household is

$$
D=S+G
$$

\footnotetext{
${ }^{19}$ In the terminology introduced by Yotopoulos and Lau (1974), this agricultural sector as modelled here is closed with respect to the labor market and regulated with respect to the output market.
} 
where $G$ is the supply of labor coming from non-agricultural households. After differentiating this equation with respect to wages and a given exogenous variable, $X$, the resulting labor market condition for equilibrating proportional changes in wages and $X$ can be written in terms of elasticities as

$$
E_{w X}=\frac{\% \Delta w}{\% \Delta X}=\left[\frac{\eta_{S X}(S / D)-\eta_{D X}}{\eta_{D w}-\eta_{S w}(S / D)-\eta_{G w}(G / D)}\right]
$$

where $\eta_{G w}$ is the elasticity of hired labor, $G$, with respect to the wage. The total response, mutatis mutandis, of a chosen endogenous variable, $Y$, to a change in a given exogenous variable, $X$, can now be written

$$
E_{Y X}=\eta_{Y X}+\eta_{Y w} \cdot E_{w X}
$$

where the first term on the right-hand side gives the response, ceteris paribus, and the second term gives the part of the total response attributable to the induced change in wages. In the analysis below eqs. (20) and (21) are applied using the values of the elasticities in table 3 and setting $S / D=0.31$. It is also assumed that the elasticity of non-padi hired labor with respect to a wage change is -0.07 , as it is for padi households in the Muda region with the production side of the model omitted ${ }^{20}$ (see table 2).

We look first at the question of surplus labor and the effect of rural-urban migration on agricultural output, a subject which has received considerable

\footnotetext{
${ }^{20}$ This assumption is valid if the utility function and the mean values of the exogenous variables delineating the characteristics of a representaiive household are the same for padi and non-padi households. Barzel and McDonald (1973) demonstrate the theoretical possibility of a negatively-sloped labor supply curve using the specification of the utility function employed in our empirical analysis. Other possible values for the elasticity of off-farm labor response were tried and the results contrasted with those obtained under the assumption that $\eta_{G w}=-0.07$. It was found that the policy results were not highly sensitive to a range of values for $\eta_{G \mathrm{w}}$ from -0.1 to 2 . That is, $\eta_{G w}$ can be negative, or positive and inelastic, or positive and moderately elastic without substantially affecting the policy implications. In contrast, for highly elastic values of off-farm labor response the results change markediy. For instance if either labor from outside the Muda area is in perfectly elasic supply to farms in Muda or a pool of surplus labor exists, then $\eta_{G w} \rightarrow \infty$ and the market elasticities would approach the household values given in table 3.

However, unlike many regions of Southeast Asia, the Muda Rìer Valley is characterized by an active labor market and an apparent lack of surplus labor. A strong indication that the outside labor supply is highly inelastic is given by observing that after the Muda irrigation project was completed there was a large increase in wages; money wage rates more than doubled between 1970 (pre-project) and 1973 'post-project), whereas the consumer price index (exclusive of rice) increased by only $15 \%$ and rice prices by less than $50 \%$ during the same period. The;, we have chosen to assume an inelastic labor supply and to consider the labor market interactions in the policy applications. But for household models estimated for other regions, where there is a strong possibility of surplus labor or an infinitely elastic laboi supply, one would apply the household response elasticities (comparable to those in table 3) directly to obtain estimates of the aggregate market response.
} 
theoretical attention in the absence of microeconomic empirical data. Based on the model introduced by Sen (1966) the discussion has focussed on the labor supply response following the departure of a family member from a household which does not participate in the labor market. In Sen's framework labor market participation is considered a sufficient condition for the constancy of per capita labor supply, since the equation of the marginal utility of leisure to an exogenously determined wage rate remains unaffected. By way of contrast our results establish that the per capita labor supply may be a function of the size of the family labor force, in which case an exogenously tetermined wage-rate is no longer a sufficient condition for a constant per capita labor supply. In our model the removal of a working member from an agricultural household will influence per capita consumption patterns through a change in the value of discretionary time available to the household and through changes in the extent of the household participation in the labor market.

Since the household has access to the labor market, the profit-maximising level of agricultural production is determined independently of the number of working family members. Following the departure of one family worker, the profit-maximising level of output can be maintained by either reducing household consumption of leisure, or increasing the quantity of hired labor or both. The economic cost of migration is determined, at least in part, by the value of $\eta_{S n_{1}}$, the elasticity of family labor supply with respect to changes in $n_{1}$. If $\eta_{s a_{1}}=1$ (i.e., the per capita labor supply of the remaining household members remains constant), then the entire impact of migration is transmitted to the labor market. Alternatively, if $\eta_{s n_{1}}=0$ (i.e., per capita labor supply increases proportionately with decreases in the number of working family members), then there is no effect on the labor market. In the event of the latter, the economic cost of migration, in the sense of foregone output, is zero, since the loss of one working family member is restored entirely by a eduction in the consumption of leisure by the remaining family members. On the other hand, if $\eta_{s n_{1}}=1$, migration will lead to a loss of output, the extent of which will be determined by the change in the agricultural wage-rate induced by the increased demand for hired labor.

In our study area in N.W. Malaysia, $\eta_{S n_{1}}$ is estimated to be 0.62 , that is, $38 \%$ of the reduction in household labor supply following the departure of one working family member is replaced by extra effort on the part of the remaining famly members, ceteris paribus. However the ultimate effect on output and thus the economic cost of migration will depend on the response of hired labor and the household to changes in the market wage. If the supply of hired labour from landiess households is perfectly elastic the economic cost of migration is zero since additional labor can be hired witho'at increasing the wage rate and hence without reducing output. Alternatively, if we assume that the non-padi hired labor supply has an 
elasticity of -0.07 as obtained from the consumption side of the nousehold models, eq\%. (20) and (21) can be used to calculate that the elasticity, $E_{D_{1}}$, of total labor hours used in padi production with respect to the number of workıng family members is 0.47 , mutatis mutandis. ${ }^{21}$ It may be concluded that migration from padi-producing households in rural Malaysia is socially beneficial provided the migrant's marginal productivity at his point of destination exceeds 0.4 .7 of his marginal productivity at his point of origin.

We next turn to an analysis of the effects of output price intervention which is an important component of current Malaysian agricultural policies designed to achieve self-sufficiency in padi. Much of the past success of Malaysia's efforts in this direction must be attributed to technological change; however the government has also intervened in the padi market to keep the domestic price above the cif price, thereby subsidizing producers.

The elasticities in table 3 establish that, at the microeconomic level, Malaysian farm households respond positively to an increase in the price of padi output: the elasticity of total output is 0.61 and that of marketed output is $\mathbf{0 . 6 6}$. However, these elasticities give the response, ceteris paribus of an individual household. If all households respond to the price increase as indicated in table 2 the supply of labor from padi households will decrease, the demand for labor will increase and the resulting potential increase in market wages may effect a reduction in output and marketed surplus which will bring about lower elasticities mutatis mutandis. The impact on the market wage will depend on the response of hired labor. Using eqs. (20) and (21) and $\eta_{G w}=-0.07$ we calculate that the elasticities of output and marketed surplus with respect to price are -0.02 and -0.08 respectively. ${ }^{22}$ We conclude that if the response of hired non-padi labor is inelastic, as we have assumed it to be, the effects of government price intervention on output and marketed surplus have been essentially nil. ${ }^{23}$

Turning to the issue of the income distributional impact of changes in output price and technology, we first examine their impact on incomes in padi households and then consider the repercussions un other sectors of the economy. As far as padi households are concerned, the microeconomic effect of an increase in (atput price or an upward saift in the production function can be derived immediately from eq. (19). Thus, the elasticity of farm profit with respect to price or the technology parameter is 1.61 . Padi households, therefore, receive a major income benefit from both price increases and technological advances, which has substantial expenditure effects on the pattern of household consumptios.

\footnotetext{
${ }^{21}$ Similarly, it can be calculated that $E_{S n_{1}}=0.58, E_{G n_{1}}=-0.02$, and $E_{F n_{1}}=0.15$.

${ }^{22}$ In contrast, the mutatis mutandis elasticities of output and marketed surplus with respect to neutral technological change are 0.96 and 1.09 respectively.

${ }^{2 s} \mathrm{As} n_{G w}$ ranges from -0.1 to 2.0 , the elasticity of output with respect to price ranges only from -0.02 to 0.11 .
} 
The associated changes in consumption and production in padi households can be expected to have a major effect on other household groups. For example, much of the increased expenditure made possible by price increases or technological advances is allocated to non-farm commodities $(M)$. The household elasticity of $M$ with respect to $p$ is 1.94 and with respect to $\alpha_{0}$ it is 2.21. Thus, the indirect effects through changes in consumption can be expected to lead to significant increases in income for those in both rural and urban areas who produce or supply non-farm commodities.

Of more importance, however, is the impact of a price increase or a technological advance on those members of the rural sector who depend primarily on wage employment as a source of income since this group is usually among the poorest in most developing countries. Increases in the price of a îajor consumption item such as padi can be expected to impose severe hardships on this group. Fortunately. however, the evidence from N.W. Malaysia indicates that this group can expect a compensating benefit in the form of increased wage income. Table 2 indicates that the household response, ceteris paribus, to a price change will involve an increase in demand for padi labor (both family and hired) and a reduction in household labor supply. The combination of an increased demand and a reduced supply of labor from padi households will effect secondary changes in the wage-rate and the use of hired labor or both.

Using eq. (21) we can calculate that $E_{w p}$, the elasticity of the market wage with respect to a change in price mutatis mutandis is 1.34 and that $E_{G p}$, the elasticity of hired labor use with respect to price, is -0.10 . Thus, the large increase in wages more than offsets the slight decline in employment and households which depend to a significant extent on wage employment as a source of income can expect an increase in their income as a result of an increase in the price of padi.

A similar effect may be expected with respect to advances in technology. Previous treatments of the effects of technological change on the labor market have tended to concentrate on the demand for labor, that is, on the production side of the model, and neglected the impact of technology on the allocation of household time between leisure and labor. ${ }^{24}$ However, our application of the farm household model indicates that there will be a sizeable response from padi farmers on both the demand and supply side of the labor market. Since the elasticity of demand for labor (both family and hired) with respect to $\alpha_{0}$ is 1.61 and the elasticity of family labor supply with respect to $\alpha_{0}$ is -0.65 , it can be expected that neutral technological change will increase the wage bill. Using eq. (20) we calculate the mutatis mutandis elasticity of the wage with respect to $\alpha_{0}$ to be 1.38 . Similarly we calculate the mutatis mutandis elasticity of hired labor use with respect to $\alpha_{0}$ to be -0.16 ,

\footnotetext{
${ }^{24}$ For example see Sidhu (1974).
} 
which implies that, although there will be some reduction in employment, neutral technological change will have a sizeable positive impact on the wage bill. This result is of considerable significance because it indicates that the 'tric'.le down' approach to economic growth is at least partially valid in that the benefits of improvements in farm technology are being transmitted through the labor market to those who are not themselves primarily padi farmers. Agricultural projects, which benefit directly those members of rural society who control the main productive assets, can also be expected to benefit those who own little or no land through changes in wage-rates and the wage bill.

\section{Conclusions}

In this paper we demonstrate the policy significance of an integrated treatment of ;. oduction and consumption decisions in the theory of the household. Cunsidering the impact of changes in exogenous variables we conclude that since the production side of the model exerts its influence on the consumption side through the expenditure elasticity, the integrated theory is especially important if either the expenditure elasticity is high or if the production effect is dominant.

In specific applications the results of the estimated model indicate that the economic cost of rural-urban migration in N.W. Malaysia is smail in relation to the marginal productivity of the migrant prior to his departure; that output price intervention is not effective in increasing marketed surplus; and that the benefits of increases in agricultural output prices and of improvements in technology are distributed through the labor market to those who rely heavily on wage employment as a major source of income.

\section{Appendix}

\section{Data sources}

The data for this study were collected during the course of one calendar year commencing December 1972 and running through to November 1973 as part of the FAO/IBRD cocperative program. The households for this survey were sampled as follows. In the first stage of the two-stage sampling procedure, a simple random sample of all rural population census enumeration blocks within the command area of the Muda River Irrigation Project (642 $i_{i}$ total) was taken using a $25 \%$ sampling fraction. Of the resulting $14,78 \varepsilon$ households, 10,196 were identified as being primarily engaged in padi work either as padi farmers or as padi farm workers.

The sample was then stratified by (i) the number of years the household had been double-cropping; and (ii) whether the land operated was acid or 
non-acid. Within each stratum thus identified, the sample size was chosen such that it bore a proportionate relationship to the standard deviation of mean annual cash income. For the purposes of our study, we have conceritrated on those households which have been double-cropping for one or more years and which operate non-acid land. This concentration ensures $a$ relatively homogeneous sample: it omits those operating on the qualitativeky inferior acid soils ( $8 \%$ of the original sample) and those who were in tî̉e process of switching from single- to double-cropping during the period of observation $(20 \%$ of the original sample). The remaining sample was then furthor adjusted to exclude (i) all households which failed to report labor usage for land preparation, planting, harvesting or threshing; (ii) all house.holds which failed to report padi output; and (iii) all households which failed to report wage payments. The final sample size is 207.

During the course of the survey each household was interviewed fifty-four times. These interviews comprised an opening ard closing inventory (which collected information on a variety of stock variables such as asset ownership and family size) and fifty-two weekly interviews (which collected information on a variety of flow variables such as expenditure, income, output and labor usage). The data from the fifty-two weekly interviews have been aggregated into thirteen four-weekly periods.

Because the survey commenced in the middle of the first crop production period, our study is confined to the second crop. That is, the planning horizon is assumed to be the second crop cycle and all variables are defined with respect to that cycle.

\section{Definition of variables}

$C$ =own-consumption of padi in gantang,

$q M=$ consumption of non-farm commodities in $M \$$,

$S$ = family labor supplied to on-farm padi production and off-farm wage employment in man-days. Male and female work time is weighted equally,

$T=$ total time available in man-days, for all working members of the family. Days lost through sickness, absences or other fluctuations in the number of working family members were netted out,

$n_{1}=$ number of working family members defined as all members of the family of 16 years of age and over,

$n_{2}=$ number of dependents defined as all members of the family under 16 years of age,

$a$ = age of the household head,

$e=$ number of years of education received by the household head,

$p=$ price of padi in $M \$$ per gantang,

$w$ = wage-rate in $M \$$ per man-day. Wages for off-farm employment were 
calculated by dividing the total value of wages received in kind or money by reported hours worked off the farm. The construction of this variable entails the use of the weakest data obtained from the survey since some households were inconsistent in reporting wage income, especially in kind. Households with obvious discrepancies in the reporting process were omitted,

$L=$ a residual which is called 'leisure' and is measured in mandays. $L=T$ $-S / 8$ on the assumption of an eight hour working day,

$E=$ total expenditure in $M \$ . E=p C+q M+w L$.

\section{References}

Abbett, M. and O. Ashenfelter, 1976, Labor supply, commodity demand and the allocation of time, Review of Economic Studies 63, 389-412.

Barnum, H.N. and L. Squire, 1978, Technology and relative Economic efficiency, Oxford Economic Papers 30, 181-198.

Barzel, Y. and R.J. McDonald, 1973, Assets, subsistence, and the supply curve of labor, American Economic Review 63, 621-633.

Becker, G.S., 1965, A theory of the allocation of time. Economic Journal 75, 493-517.

Berry, A. and R. Soligo, 1968, Rural-Urban migration, agricultural output and the supply price of labour in a labour surplus economy, Oxford Economic Papers 20, 230-249.

Chayanov, A.K., 1966, The theory of the peasant economy (Irwin, Homewood, IL).

Deaton, A., 1974, A reconsideration of the empirical implications of additive nreferences. Economic Journal 82, 1115-1236.

Jorgenson, D.W. and L.J. Lau, 1969, An economic thecry of agricultural household behaviou, Taper presented at the Far Eastern Meeting of the Econometric Society (Tokyo).

Khrishna, R., 1969, Comment: Models of the family farm, in: C.R. Wharton, Jr., ed.. Subsistence agriculture and economic development (Aldine, Chicago, IL).

Lau, L.J., W.L. Lin and P.A. Yotopoulos, 1978, The linear logarithmic expenditure system: An application to consumption-leisure choice, Econometrica 46, 843-868.

Lau, L.J. and B.M. Mitchell, 1970, A linear logarithmic expenditure system: An application to U.S. data, Paper presented at the Second World Congress of the Econometric Society (Cambridge).

Lau, L.J. and P.A. Yotopoulos, 1971, A test of relative efliciency and application to Indian agriculture, Amer ian Economic Review 61, 94-109.

McFadden, D.L., 1970, Cost, revenue, and profit functions, mimeo. (Department of Economics. University of Calitornia, Berk-ley, CA)

Nakajima, C., 1969. Subsistence and cominercial family farms: Some theoretical models of subjective equilibrium, in: C.R. Wharton, Jr., ed., Subsistence agriculture and economic development (Aldine, Chicago, IL).

Nowshirvani, N.F., 1966, Allocation efficiency in traditional Indian agriculture: Comment, Journal of Farm Economics 49, 218-221.

Sen, A.K., 1966, Peasants and dualism with or without surplus labor, Journal of Political Economy 74, 425-450.

Sidhu, S.S., 1974, Economics of tèchnical change in wheat production in the Indian Punjat. American Journal of Agricultural Economics 56, 217-226.

Stone. J.R.N., 1954, Linear expenditure systems and demand analysis: An application to the pattern of British demand, Economic Journal 64. 511-527.

Theil. H., 1975. Theory and measurer lunt of consumer demand (North-Holland. Amsterdam). 
Yotopoulos, P.A. and L.J. Lau, 197; On modelling the agricultural sector in developing countries, Journal of Development $E$;onomics 1, 105-127.

Zeliner, A.J., J. Kmenta and J. Dreze, 1966, Specification and estimation of Cobb-Douglas production function models. Econometrica 34, 784-795. 